\title{
Research on Innovative Financing System of Small and Micro Businesses Based on Big Data Rating
}

\author{
Xiaomeng Liu ${ }^{1,2, *}$, Changxin $\mathrm{Xu}^{1}$ \\ ${ }^{1}$ School of Business, Hohai Univiersity, Nanjing, 211100, China \\ ${ }^{2}$ School of Business, Jinling Institute of Technology, Nanjing, 211169, China \\ * Corresponding Author: Xiaomeng Liu
}

Keywords: Financing system, Small and micro businesses, Big data, Credit rating

\begin{abstract}
We can make use of the internet financing platform to carry out credit rating based on big data technology to provide financing services for small and micro enterprises, which has become an important form of internet finance. This paper analyzes the advantages, theoretical basis and implementation process of enterprise credit rating based on large data. Through the aspects of encouraging the development of third party rating agencies, improving the index system of credit rating and formulating legal system of risk prevention, small and micro businesses can obtain more finance help.
\end{abstract}

\section{Introduction}

For small and micro businesses, the growth of the road has many obstacles. The difficulty of financing is the biggest stumbling block to the development of small and micro enterprises. All along, the traditional financial profit model is due to the information asymmetry between capital supply and demand for funds, the single fund supply to save such as search, negotiation, transaction, supervision costs for banks as their investment agents, banks to collect funds for the agency cost, which is the bank's loan balance. The interest rate difference between the deposit and loan is the foundation of the traditional financial profit model. However, because the interest rate of the traditional financial institutions is not marketization, the money providers can only get fixed income. To ensure the stability and security of the profits, the focus of the traditional financial institutions is to control the loan issuance. Therefore, the traditional financial loan market is a seller's market, and its investment logic is to identify the needs of the fund carefully, to ensure profits on the basis of fund safety. For small and micro enterprises, different from large enterprises, the information disclosure of large enterprises is full, the credibility is high, and the information audit is easy. The information disclosure of small and micro enterprises is less, the quality of information is low, the financial statements are not sound, and there is no definite information to reflect the real business situation of the enterprise. China social credit system is still not fully established, only to establish some system of bank customer credit, most of which are for large and medium-sized enterprises or individual housing loans of Small and micro businesses without any credit system can query, often encountered the plight of the lack of public information on the evaluation of information Small and micro businesses when. Therefore, this has improved the credit evaluation cost of small and micro enterprises in the traditional financing mode, making the financing costs of small and micro enterprises far higher than that of large enterprises.

\section{Credit Rating Based on Big Data}

\subsection{Advantages of Credit Rating Based on Big Data}

The amount of information is large and the result of credit rating is more objective and accurate. Large data rating can reduce the credit cost and financing cost of small and micro enterprises. Ali 
small loan customer manager through the Internet online survey, relying on a large amount of information accumulated, can quickly analyze the debtor's economic data at home, judge the debtor's financial and business situation, and accurately assess his credit risk. In addition, the rapid approval of the Ali loan is only a few minutes to complete, and the fastest loan funds can be reached within 1 days. But every customer manager in a commercial bank is the limit to manage one hundred customers. The management of Ali small loan credit account manager can be as high as one thousand. Because of the advantages of large data collection, such as low cost and ability to be batch, it has the advantage of scale economy on the Internet financing platform. The traditional way of credit rating needs to carry out pre-credit investigation, loan review and loan tracking. As a result, the average cost of each enterprise is gradually reduced, which makes it easier to achieve the scale effect of credit rating. Large data ratings can make the rating results more reliable and timely. Large data mining and rapid analysis of rating information through cloud computing technology, real-time monitoring of the enterprise. Once a company has dangerous signals and actions, it will immediately alert and enhance the prejudgment of credit rating. It can detect abnormal situations in time by dynamically grasping customer transaction data. The big data technology takes the risk level of enterprises in the whole industry chain to grasp, which is more forward-looking to the change of external economic environment and the occurrence of enterprise default risk, and helps to improve the pro cyclical nature of credit rating industry.

\subsection{Theory of Credit Rating Based on Big Data}

The assumption of rational economic man is a classic hypothesis in economics, but because of the complexity of the economic situation and the limitation of cognition ability, economic man in decision making often show limited rationality. The beginning of the optimal strategy cannot or will not completely rational conditions. Evolutionary game simulation of economic man in irrational conditions, through competition and cooperation and other behaviors to learn from each other, adjust behavior strategy, and ultimately achieve the strategy of evolutionary stability. Customers in the loan application, the website will automatically collect customer information online: evaluation scores, store profitability, cash flow size store management condition scoring system network of shops, through these online information, the comprehensive risk assessment of the loan compared with other small and micro loans, the online system is the most distinctive part of small loan the accuracy of dynamic data, all customers in various websites and its website for online system provides a guarantee of loan evaluation results. It has accumulated huge amounts of data, the value of this remarkable grassroots credit system. All kinds of account and flow accounts provide valuable and accurate data support for Ali credit services. This comprehensive customer evaluation system can help financiers better understand the level of the borrower's capital and credit rating, and effectively reduce the risk of the loan. When deciding whether to provide loans to applicants, the financing party must first confirm that the order is real, and calculate the possibility of fraud in the online shops of the applicant. Whether the transaction in the applicant's shop is concentrated in a period, whether the buyer is so many people. The website also collects applicants' offline information by other external means, such as their personal background, the level of integrity and the shop operation plan.

\subsection{Process of Credit Rating Based on Big Data}

The first step in implementing large data rating is to understand the evaluation of the project. First, we should grasp the contents of the project operation mode, customer characteristics, market status and risk constitution. Secondly, we will design the project plan according to the understanding of the project content, including arranging the feasible technological route of the project, and making the progress of the project. Again, when the project plan is to determine the source of big data after, because of the large data sources although many, but will be subject to various restrictions, such as some may be too expensive, some do not open, must choose the technology and economy is feasible as a data source. Therefore, it is necessary to prepare these items before the project is formally implemented, based on the understanding of the project. The second step is to prepare the data. The work done is: according to the data sources, determine the type of data, take feasible data collection 
technology, data acquisition; incomplete, repeat, there are many defects such as error data to preprocess data; data after preprocessing if a non-structured or semi-structured data, needs formatting, transformation for structured data, get ready for the next step. And the big data rating technology has the total cost fixed characteristics in data collection, model rating and post loan management. With the increase of the number of rating enterprises, the total cost does not change significantly. The third step is to do machine learning. The first is the rational choice of data mining techniques to analyze the data, find the relationship from, followed by the interpretation and evaluation of the data mining results, find the most reasonable and persuasive, realize knowledge discovery; finally, is based on knowledge discovery, to establish a credit rating model for. The fourth step is to implement the rating. According to the model of knowledge discovery, credit rating of the rated objects is carried out, and the rating report is generated, and the conclusion is analyzed to help customers understand the rating results. Finally, a comprehensive summary of the operation of the whole project is made.

\section{Innovative Financing System of Small and Micro Businesses}

\subsection{Encourage the Development of Third Party Rating Agencies}

We should introduce policies to encourage the development of independent third-party rating agencies, introduce excellent talents in the industry, and create a group of rating agencies with strong professional skills and market competitiveness. The relevant regulatory authorities should formulate a legal system to maintain the credibility of the credit rating industry and improve the influence of the credit rating agencies in the financial sector. We encourage all commercial banks and other financial institutions to conduct credit rating on small and micro businesses through third party rating agencies, and gradually form rating reports to become an important basis for financial institutions to approve loans, so as to truly play the role of rating agencies. In the specialization mode, Guarantee Corporation Based on the profit maximization goal, under the perturbed uncertainty risk, the guarantee scale of its supply is usually lower than the effective demand of the entity enterprise. The lower the qualification of SMEs, the higher the degree of information asymmetry, the worse the risk compensation rate of the professional guarantee, the lower the supply of credit guarantee. In the mutual aid mode, the degree of information symmetry between the internal members is high. Even if there is an asymmetry, the risk can be hedged by the internalization of external economy. Therefore, the supply of mutual guarantee is not restricted by the risk profit, and is equal to the effective demand of the cooperative member enterprises. In the low-level enterprise, the performance of mutual aid guarantee organization is superior to the specialized Guarantee Corporation. The government should encourage innovative forms of security and increase support for security institutions. The government should introduce laws to encourage diversified forms of mortgage and pledge, such as the pledge of accounts receivable, anti-guarantee. In addition, although the government has taken various measures to support the establishment of guarantee institutions, though the government has taken various measures to solve the plight of SME financing, there are still many shortcomings, such as a small number of guarantee institutions in underdeveloped areas, and a narrow source of financing for guarantee institutions. Therefore, the state should continue to introduce laws and regulations, take the way of administrative guidance, and provide funds to support the establishment of security institutions.

\subsection{Improve the Index System of Credit Rating}

We can dynamically improve the credit rating index system by means of large data. The use of big data can achieve the transformation of unstructured data into structured data, which can more conveniently tap valuable data and establish a rating index system that is suitable for small and micro businesses. At the same time, the large data can take all kinds of information at any time, and can realize the dynamic adjustment of the credit rating index system of small and micro enterprises. Such data have continuity, and it is convenient for financial institutions to grasp the business situation in time and form a credit early warning mechanism. Credit rating agencies should formulate a set of 
rating standards different from ordinary enterprises according to the special circumstances of small and medium-sized enterprises, to make more reasonable credit evaluation for private debt. The state should strengthen the support of the credit rating agencies and enhance the credibility of the local rating agencies. The regulatory authorities should also take legal means to supervise credit rating agencies to provide a fair and accurate rating. The society should establish a sense of credit rating. All market economy subjects should go through credit rating. Financial institutions must carry out credit rating. Customers have the right to know their credit situation and have the right to make business choices based on their credit conditions. Based on credit rating, we set up the credit warehouse of enterprises, individuals and financial institutions. Banks and enterprises can easily understand the credit status of customers through payment methods. Design and improve the scientific credit rating index system and evaluation standard is the foundation of the credit rating industry. We should improve the objectivity, fairness and accuracy of credit rating, and develop a set of rating frameworks, rating indicators and rating methods that can guide credit rating agencies to enhance the scientific, rationality, social standardization and international applicability of China's credit rating. Therefore, the emphasis should be placed on improving and improving the credit rating index system and rating standards for a period.

\subsection{Formulate Legal System of Risk Prevention}

The regulatory authorities shall formulate legal prevention and control systems. The regulatory authorities should intensify cooperation and share information exchanges, establish pre - prevention and post punishment mechanisms, and constantly innovate the legal prevention and control system that meets market demand. Financial institutions credit checks on Small and micro businesses, can through legal means, signed a contract to obtain the purchase of loans in the repayment period of the fixed assets of enterprises of all fixed assets or the borrower of personal assets in the right to know, and when the failure of the priority disposal project. In the case of real failure, the bankruptcy liquidation and asset auction can be used to compensate the financial institution's loan loss. To take the concealed strategy, once verified, recover the enterprises of all project income and fixed assets, and the borrower cannot obtain any loans for life. All the information on the failure of the loan is published in the specific media. Because the stock market has many financing function, can improve the small and medium-sized enterprises to invest a lot of money demand, but also the introduction of competition mechanism, the market prospect of the enterprise has not eliminated, thus launched a wider innovative, high growth, the development of the gem in the earlier stages of small and medium-sized enterprises, will be able to make a part of entrepreneurship the enterprise group is the most outstanding market through the issuance of direct financing; at the same time to provide exit mechanism, greatly promote venture capital and private equity investment of more small and medium-sized enterprises; but also through the demonstration effect of the capital market, stimulate more small and medium-sized joint-stock enterprises, improve corporate governance and standardize the operation, reduce the risk of the level, which led to banks and other credit guarantee agencies, and local governments to increase support for enterprises.

\section{Conclusion}

The financing of the Internet platform based on big data has become an important form of internet finance. In the future, in addition to further developing and innovating credit data mining technology and rating technology in theory and practice, we also need to establish legislation supervision for the big data industry to ensure that the subject of credit is not infringed while obtaining financing services.

\section{Acknowledgement}

This research is the result of Jiangsu University Philosophy and Social Science Fund Project (2017SJB0481). 


\section{References}

[1] Huang Zijian, Wang Yan. Big data, Internet Finance and Credit Capital: Resolving Small and Micro Businesses Financing Paradox [J]. Financial Economics Research, 2015, 30(1): 55-67.

[2] He Fei, Zhang Bing. Internet Finance: Big Data-driven and Pattern Evolution [J]. Finance \& Economics, 2016(6): 12-22.

[3] An Xiaoxue. A Review of the Researches on Big Data Credit Rating and Internet Financing [J]. Credit Reference, 2017(5): 54-57.

[4] Zhang Xiangdong, Zhong Weiya. Reconstruction of Credit Rating Industry In the Big Data Era [J]. Journal of Social Science of Hunan Normal University, 2014(6): 95-100. 